domov www.zdravgozd.si

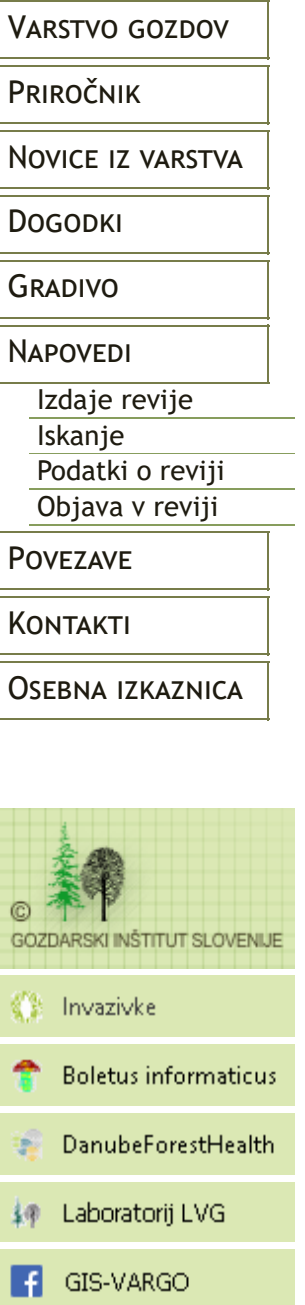

Varstvo gozdov / Napovedi o zdravju gozdov / Napoved

Kratki znanstveni prispevek

Napovedi o zdravju gozdov, 2019 DOI: $10.20315 /$ NZG. 51

\title{
Kratkoročna napoved ulova osmerozobega smrekovega lubadarja (Ips typographus) v kontrolne pasti tipa Theysohn za leto 2019 za Slovenijo
}

\author{
Maarten DE GROOT ${ }^{1}$, Marija KOLŠEK ${ }^{2}$ \\ ${ }^{1}$ Gozdarski inštitut Slovenije, Večna pot 2, 1000 Ljubljana; ${ }^{2}$ Zavod za gozdove Slovenije, Večna pot 2, 1000 \\ Ljubljana \\ *maarten.degroot@gozdis.si
}

Datum izdaje: 16.09 .2019

Veljavnost: 2019

Ključne besede: Ips typographus, osmerozobi smrekov lubadar, prenamnožitev, napoved, navadna smreka, pasti, Picea abies, gostota populacije, Slovenija

Uvod

V letu 2018 je bilo po podatkih Zavoda za gozdove Slovenije (ZGS) za posek izbranih za 698.200 $\mathrm{m}^{3}$ od žuželk napadenih dreves, posekanih pa $737.500 \mathrm{~m}^{3}$, od tega $99 \%$ zaradi smrekovih podlubnikov, v glavnem osmerozobega smrekovega lubadarja (Ips typographus L.). Posek je večji od količine izbranih dreves za posek, ker vključuje tudi posek dreves, izbranih za posek v predhodnem letu. Večje poškodbe so smrekovi podlubniki povzročili v GGO Bled, kjer je bilo evidentiranega 47 \% vsega poseka zaradi žuželk v letu 2018. O prenamnožitvi populacije osmerozobega smrekovega lubadarja so zaposleni ZGS poročali tudi iz območij večje poškodovanosti gozdov v vetrolomu iz decembra 2017, zlasti iz gozdnogospodarskega območja (GGO) Kočevje, čeprav iz evidence poseka prenamnožitev smrekovih podlubnikov na teh območjih v letu 2018 ni bila zaznana. Posek v vetrolomu poškodovanih smrek, ki so jih naselili podlubniki, je namreč evidentiran kot posek zaradi vetra in ne posek zaradi žuželk, saj se v evidenci poseka praviloma beleži primarni vzrok poseka. $V$ drugih predelih Slovenije $v$ letu 2018 niso imeli veliko težav zaradi podlubnikov (ZGS, 2019).

V letu 2019 je bilo prvo rojenje podlubnikov evidentirano že v drugi dekadi marca, kar je posledica nadpovprečno toplega začetka leta (Cegnar 2019a). Temu je sledil nadpovprečno hladen in deževen maj (Cegnar 2019b). Vremensko dogajanje je vplivalo na prvo rojenje podlubnikov, ki se je razvleklo na daljše obdobje, ter na povečano število izbruhov. Zaradi veliko površinskih poškodb gozdov v vetrolomih 2017 in 2018 ter zaradi že obstoječe visoke gostote podlubnikov je bila v letu 2019 napovedana prenamnožitev podlubnikov (de Groot in sod., 2018). Vendar je v primerjavi z letom 2018 prišlo le do manjšega dviga števila kontrolnih pasti, kjer je prišlo do prenamnožitve populacije osmerozobega smrekovega lubadarja (Ogris in Kolšek, 2019).

Cilj te študije je bil napovedati število ulovljenih osebkov osmerozobega smrekovega lubadarja $\checkmark$ pasteh za sredino avgusta 2019. Preučili smo časovne trende rasti populacije za prvo generacijo osmerozobega smrekovega lubadarja v prvi polovici leta 2019, na podlagi katerih smo pripravili kratkoročno napoved številčnosti populacije Ips typographus za sredino avgusta 2019, ko je bil pričakovan vrh drugega rojenja podlubnikov.

\section{Metode dela}

Mreža kontrolnih pasti za spremljanje gostote populacij smrekovih podlubnikov

Spremljanje gostote populacij smrekovih podlubnikov v Sloveniji opravlja Zavod za gozdove Slovenije (Kolšek in Jakša, 2012). V letu 2019 se je spremljalo 3.126 pasti tipa Theyson®, ki so bile razporejene na različnih lokacijah po vsej Sloveniji. Za privabljanje hroščev so pasti opremljene s specifičnimi feromonskimi pripravki za privabljanje dveh najbolj problematičnih vrst smrekovih podlubnikov, t.j. osmerozobega smrekovega lubadarja (Ips typographus) in šesterozobega smrekovega lubadarja (Pityogenes chalcographus). Za privabljanje 
osmerozobega smrekovega lubadarja, ki ga obravnava ta napoved, je bil praviloma uporabljen proizvod IT - Ecolure Tubus, v manjšem številu IT - Ecolure Tubus Mega in Pheroprax. V napovedi smo predpostavili, da vsi uporabljeni feromonski pripravki enako učinkovito privabljajo hrošče vrste Ips typographus. Na posamezni lokaciji je lahko postavljeno različno število pasti: ena (enojna past), dve (dvojna past) ali tri (trojna past) pasti. $V$ nekaterih primerih (dvojne in trojne pasti) je bila poleg vabe za Ips typographus tudi vaba za Pityogenes chalcographus. Pasti so bile postavljene na razdalji 10-25 m od smrek.

Analizirani so bili podatki o ulovu v kontrolne pasti v letu 2019, ki so bili vneseni v računalniški program Varstvo gozdov do 23. 7. 2019 (Ogris, 2012). Vsaka past ima naslednje podatke: lokacija, datum postavitve pasti, vrsta pasti (enojna, dvojna, trojna), vrsta feromonske vabe in datum vstavitve oziroma menjave vabe, ime osebe, ki je izpraznila past, datum praznjenja pasti in količina ulovljenih hroščev osmerozobega smrekovega lubadarja $(\mathrm{v} \mathrm{mL})$. Na podlagi prostornine ulovljenih hroščev se izračuna njihovo število s pomočjo pretvorbenega faktorja, in sicer $1 \mathrm{~mL}$ hroščev I. typographus številčno pomeni 40 osebkov te vrste.

\section{Razvoj modela}

Za razvoj modela smo uporabili le del zbranih podatkov, in sicer je bila past upoštevana $v$ analizi le, če je bila kontrolirana (izpraznitev pasti) vsaj petkrat v obravnavanem obdobju. Ker je bilo v določenih primerih na eni lokaciji postavljenih več pasti skupaj (enojna past, dvojna past, trojna past), je bilo treba število ulovljenih hroščev korigirati s številom pasti na lokaciji, saj se beleži le skupna količina ulova na lokacijo. Korekcijo smo izvedli tako, da smo skupno količino ulova v pasti delili s številom pasti na lokaciji. Skupaj smo na ta način za leto 2019 pridobili podatke o ulovu iz 2.064 pasti.

Za vsako od teh pasti smo izračunali kumulativno število hroščev ujetih od 1. 3. 2019 do 23. 7. 2019. Podatke smo analizirali s posplošenim linearnim modelom (GLM) (Zuur in sod., 2009). Za model smo uporabili kumulativno število hroščev kot odvisno spremenljivko, identifikacijsko številko pasti, dan v letu in njuno interakcijo pa kot neodvisne spremenljivke. Model smo preverili s pomočjo Pearsonovega ostanka za vsako neodvisno spremenljivko.

Preverili smo, če je $v$ pasteh prišlo do prekoračitve praga 9.000 hroščev $I$. typographus na past. Sledila je napoved s pomočjo modela za napoved številčnosti osebkov $I$. typographus na dan 15. 8. 2018 za vsako kontrolno past, ki je bila vključena v analizo. Vse analize so bile izvedene s pomočjo statistične programske opreme R (R Development Core Team, 2011). Napovedi smo preverili z regresijo merjenih podatkov. $S$ prilagojenim koeficientom determinacije $R^{2}$ (glede na stopinje prostosti) je bila potrjena skladnost napovedanih vrednosti z merjenimi. Podatki o ulovu $v$ kontrolne pasti so bili preneseni iz računalniškega programa Varstvo gozdov 20. 7. 2019 in analizirani v avgustu 2019.

\section{Rezultati in razprava \\ Časovni trendi}

Začetek prvega rojenja osmerozobega smrekovega lubadarja v letu 2019 smo zabeležili v GGO Novo mesto že 11. marca, v Ljubljani pa 14. aprila. Številčnost populacije podlubnikov je bila nizka in do konca spomladanskega rojenja kumulativni ulov večinoma ni presegel praga 9.000 osebkov (Ogris in Kolšek, 2019). V primerjavi z letom 2018 (de Groot in sod., 2018) je začetek rojenja v letu 2019 v večini pasti nastopil v enakem obdobju. V letu 2018 je bil prag 9.000 osebkov presežen v manjšem številu pasti kot v letu 2019 (Ogris in Grecs, 2018). 

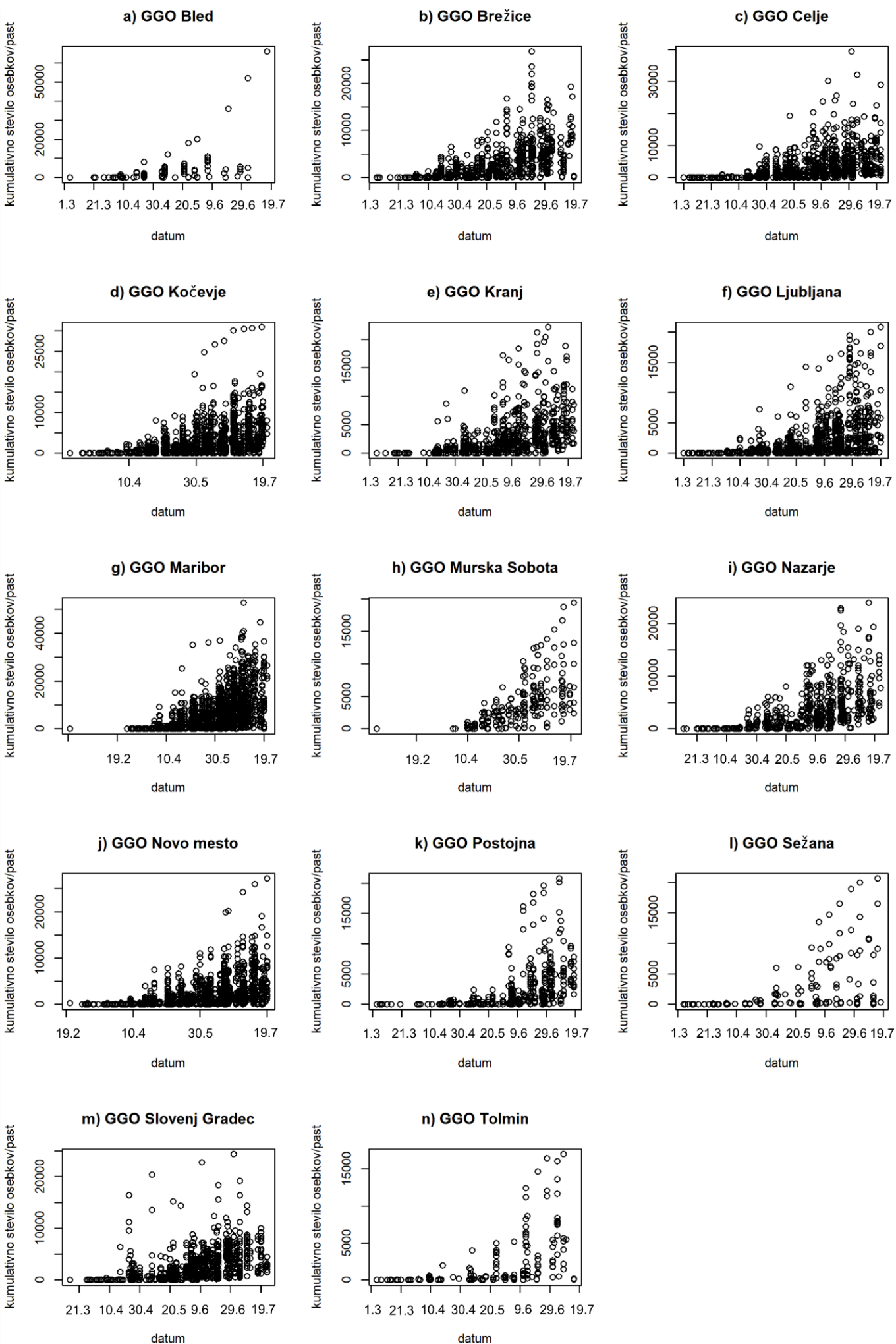

Slika 1: Trend številčnosti ulova hroščev Ips typographus v kontrolne pasti po gozdnogospodarskih območjih (GGO) v 2019.

\section{Kratkoročna napoved}

Model, ki smo ga uporabili za napoved gostote populacije osmerozobega smrekovega lubadarja v sredini avgusta 2019, je zanesljiv, saj pojasni kar $87 \%$ variabilnosti podatkov $\left(R^{2}=0,87\right)$. Model je na voljo za vpogled pri prvemu avtorju članka.

Letošnja napoved števila ulovljenih osebkov osmerozobega smrekovega lubadarja $v$ kontrolnih pasteh v Sloveniji za sredino meseca avgusta 2019 kaže, da bo na ravni Slovenije večji kot v enakem obdobju leta 2018 (de Groot in Grecs, 2018). Glede na model se bodo sredi avgusta 2019 prenamnožitve osmerozobega smrekovega lubadarja pojavljale lokalno na območju celotne Slovenije. (slika 2). Model napoveduje, da so najbolj problematična območja glede prenamnožitve vrste Ips typographus v letu 2019 GGO Maribor, GGO Nazarje, GGO Slovenj Gradec, GGO Kranj, GGO Bled in GGO Kočevje. 


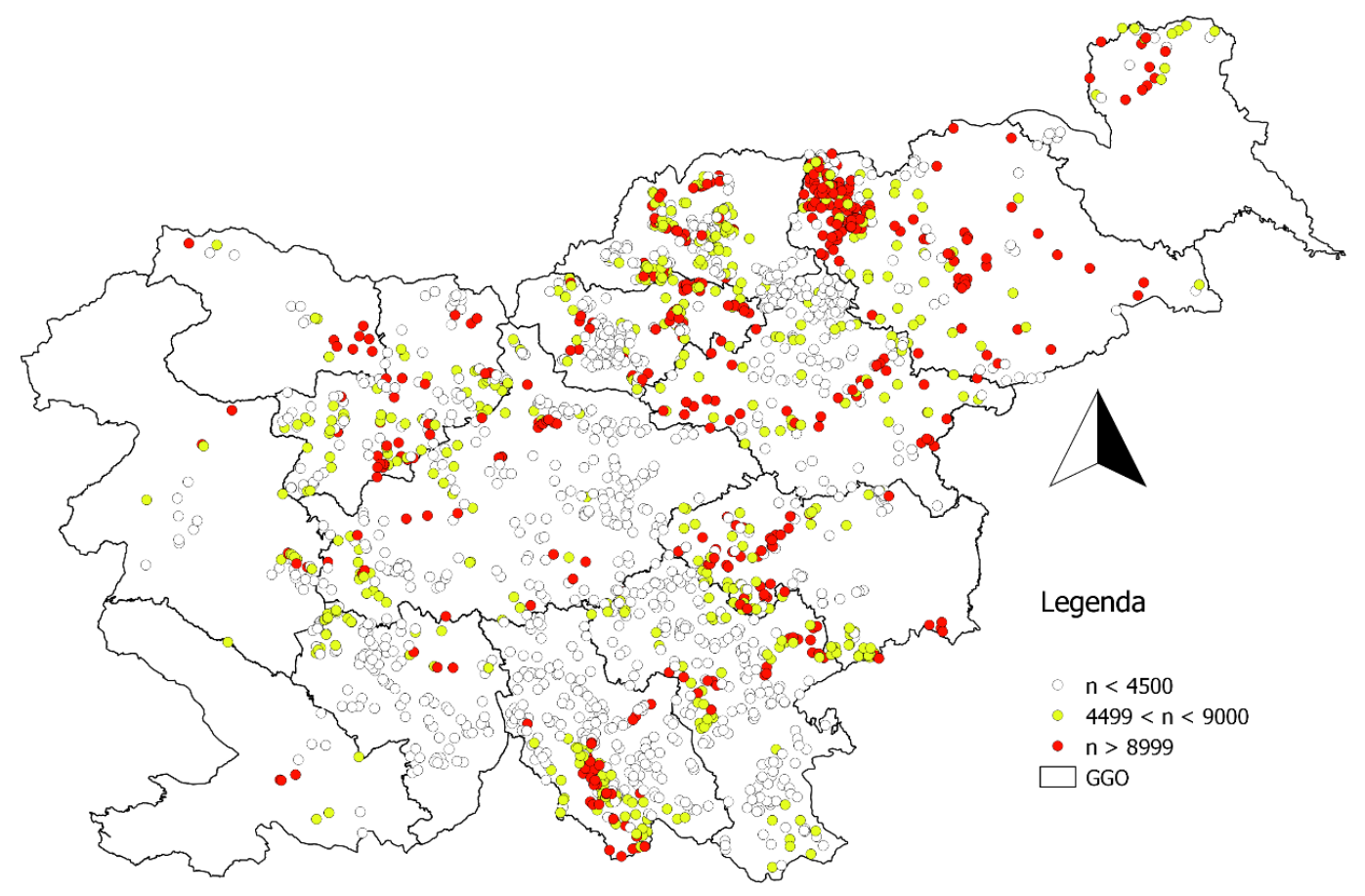

Slika 2: Napoved števila osebkov osmerozobega smrekovega lubadarja v kontrolnih pasteh za sredino avgusta 2019 za posamezne kontrolne pasti na območju Slovenije. Vir GGO sloj: Zavod za Gozdove Slovenije.

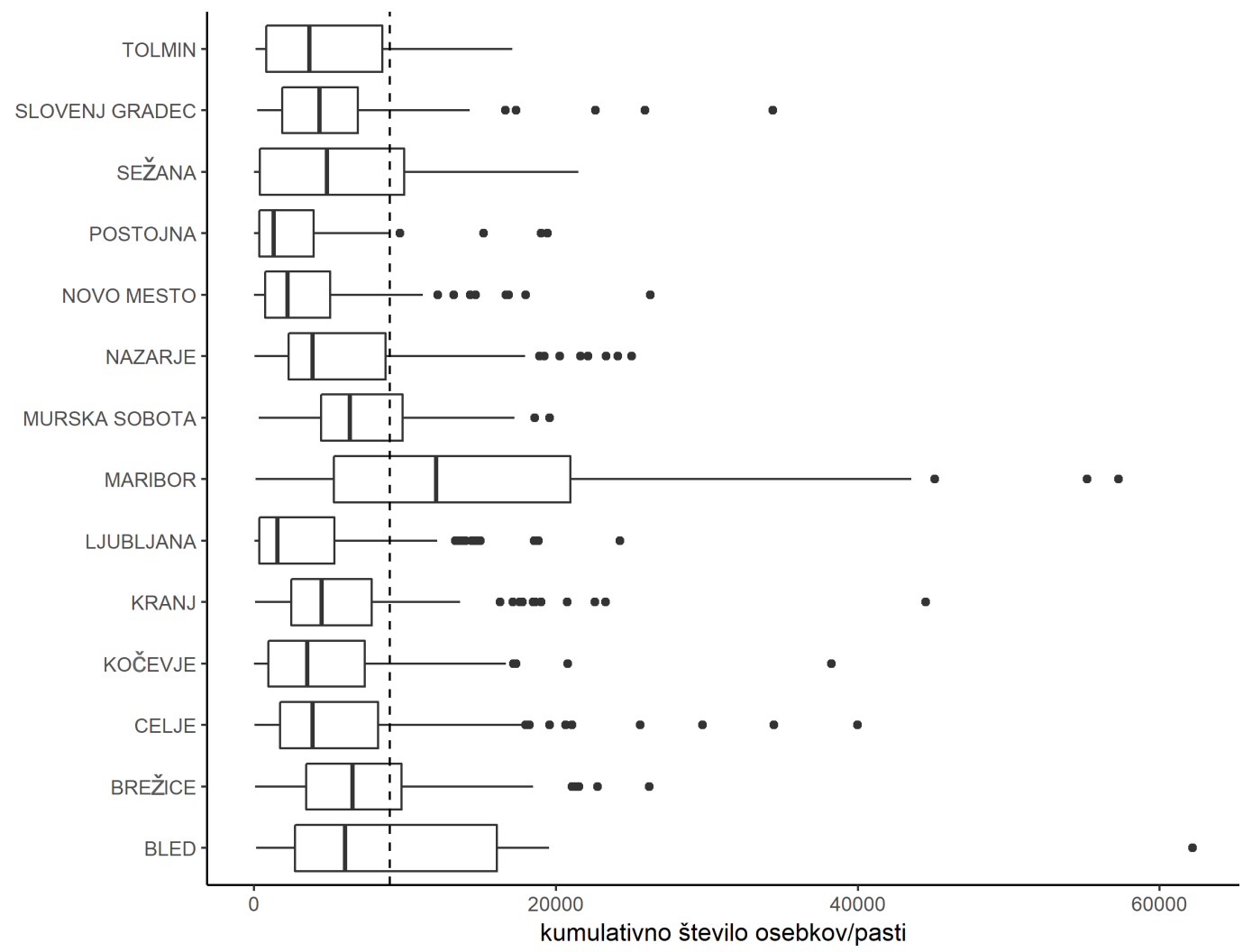

Slika 3: Napoved števila osebkov osmerozobega smrekovega lubadarja v kontrolnih pasteh za sredino avgusta 2019 po GGO-jih. Za primerjavo povprečnega kumulativnega ulova v past na ravni GGO smo prikazali 9.000 osebkov, ki je prag za prenamnožitev ob koncu prvega rojenja.

V preteklem letu (2018) je bil na ravni GGO do sredine avgusta napovedan največji kumulativni ulov vrste Ips typographus v GGO Bled, GGO Nazarje in v GGO Tolmin. V letu 2019 je največji kumulativni ulov na ravni GGO do sredine avgusta napovedan v GGO Maribor (Slika 3). To je bilo že pričakovano, saj sta tudi Ogris in Kolšek (2019) opazila to povečanje. Na splošno po vsej Sloveniji opažamo enaka razmerja med kumulativnimi ulovi v pasteh kot konec julija 2019 (Ogris in Kolšek 2019). Zlasti v okolici pasti z ulovom nad pragom 9.000 hroščev do konca julija opažamo napovedan nadpovprečni kumulativni ulov $v$ tej študiji. To pomeni, da je populacija prenamnožena na širšem območju.

Za zanesljivejšo prognozo je pomembna visoka gostota kontrolnih pasti, ki jih redno spremljamo. Na splošno je večina Slovenije s pastmi pokrita, vendar ne enakomerno. Na območju smrekovih gozdov v GGO Bled (Jelovica) in GGO Tolmin (Trnovski gozd) ni bilo dovolj pasti za kakovostno napoved. Zato predlagamo, da se $v$ naslednjih letih zagotovi spremljanje 
gostote populacij smrekovih podlubnikov s povečanjem števila feromonskih pasti na teh območjih. Zaradi manjšega števila pasti, zajetih v analizo za GGO Bled in GGO Tolmin, sta napovedi za 2019 manj zanesljivi.

Iz slike 4, ki prikazuje evidentirano količino iglavcev za posek zaradi napada podlubnikov v letu 2019 (do 25. junija), je razvidno, da se prenamnožitev smrekovih podlubnikov v GGO Bled nadaljuje. Večje poškodbe so zabeležene tudi v GGO: Kočevje, Slovenj Gradec, Maribor, Nazarje in Kranj.

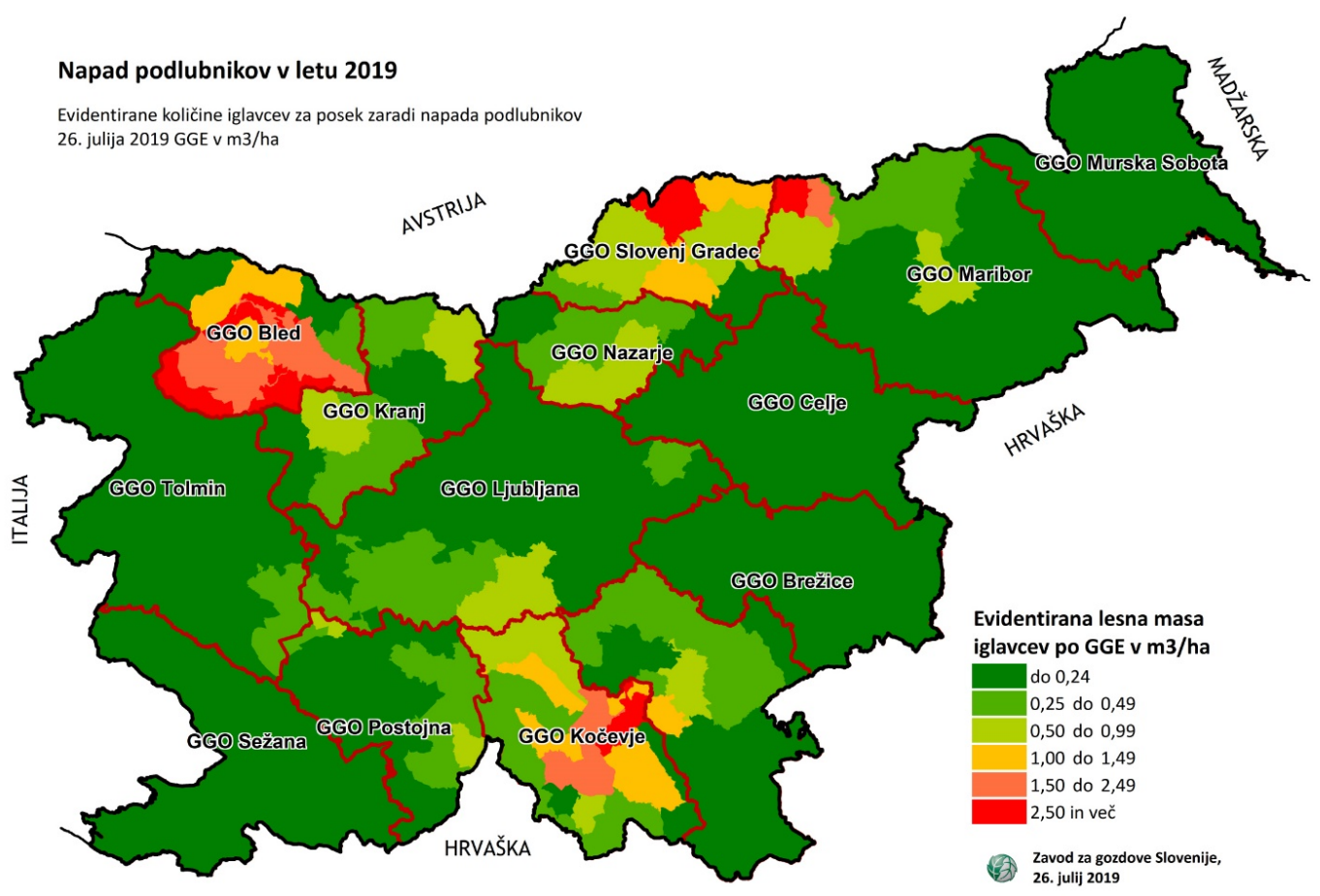

Slika 4: Evidentirana količina iglavcev za posek zaradi napada podlubnikov od 1.1. - 26. 7. 2019. Vir: Zavod za Gozdove Slovenije, podatki o izbiri dreves za posek.

\section{Zaključek}

V prispevku smo predstavili stanje in napovedali število ulovljenih osebkov osmerozobega smrekovega lubadarja v kontrolnih pasteh za sredino avgusta 2019. Glede na rezultate raziskave moramo še naprej izvajati vse potrebne ukrepe za omejevanje širjenja populacije osmerozobega smrekovega lubadarja. Kot najbolj problematična območja v letu 2019 se kažejo GGO na alpskem območju (GGO Maribor in GGO Bled) ter GGO Kočevje. Situacija se lahko razplete drugače, kot je napovedano $v$ tej raziskavi, in sicer zaradi variabilnosti okoljskih dejavnikov, ki vplivajo na ulov hroščev $v$ feromonske pasti. Variabilnosti okoljskih dejavnikov, njihovih vrednosti in vpliva na ulov pa ni mogoče $v$ celoti predvideti. Na razvoj podlubnikov imajo zelo velik vpliv vremenske razmere. Do sredine avgusta 2019 so bili zabeleženi že štirje vročinski valovi (Cegnar 2019c, Cegnar 2019d), ki so pospešili razvoj podlubnikov. Posledica je manj razpoložljivega časa za najdbo žarišč podlubnikov, posek napadenih dreves in uničenje zalege. Zato lahko pričakujemo zelo številčno drugo generacijo podlubnikov in povečanje škode, ki bo nastala zaradi podlubnikov, v drugi polovici leta.

\section{Zahvala}

Raziskava je nastala v okviru Javne gozdarske službe na Gozdarskem inštitutu Slovenije in Zavodu za gozdove Slovenije. Zahvaljujemo se recenzentoma za koristne predloge izboljšav članka.

\section{Viri}

Cegnar T. 2019a. Podnebne razmere v marcu 2019. Naše okolje, 26, 2: 3-26.

Cegnar T. 2019b. Podnebne razmere v maju 2019. Naše okolje, 26, 2: 3-26.

Cegnar T. 2019b. Podnebne razmere v juniju 2019. Naše okolje, 26, 2: 3-27.

Cegnar T. 2019c. Podnebne razmere v juliju 2019. Naše okolje, 29, 2: 3-25.

De Groot M, Grecs Z. 2018. Kratkoročna napoved ulova osmerozobega smrekovega lubadarja (Ips typographus) v kontrolne pasti tipa Theysohn za leto 2018. Napovedi o zdravju gozdov, 2018. Povezava: https: / / www.zdravgozd. si/prognoze zapis.aspx?idpor=40

De Groot M., Ogris N., Kobler A. 2018. The effects of a large-scale ice storm event on the drivers of bark beetle outbreaks and associated management practices. Forest Ecology and Management, 408: 195-201. Povezava: https://doi.org/10.1016/j.foreco.2017.10.035

Jakoby O., Lischke, H, Wermelinger B. 2019. Climate change alters elevational phenology patterns of the European spruce bark beetle (Ips typographus ). Global Change Biology, 2019. Povezava: https://doi.org/10.1111/gcb.14766 
Kolšek M, Jakša J. 2012. Osmerozobi smrekov lubadar - Ips typographus, šesterozobi smrekov lubadar - Pityogenes chalcographus. V: Jurc D., Kolšek M. Navodila za preprečevanje in zatiranje škodljivcev in bolezni gozdnega drevja v Sloveniji. Ljubljana, Silva Slovenica, Gozdarski inštitut Slovenije: 104 str.

Ogris N., Grecs Z. 2018. Namnožitev osmerozobega in šesterozobega smrekovega lubadarja v Sloveniji v 2018. Napovedi o zdravju gozdov, 2018. Povezava:

https: / / www.zdravgozd.si/prognoze zapis.aspx?idpor=39

Ogris N., Kolšek M. 2019. Namnožitev populacij osmerozobega smrekovega lubadarja in šesterozobega smrekovega lubadarja v Sloveniji v 2019. Napovedi o zdravju gozdov, 2019. Povezava: https: / / www.zdravgozd.si/prognoze zapis.aspx?idpor $=50$

Ogris N. 2012. Prognostične osnove za varstvo gozdov Slovenije. Ljubljana, Silva Slovenica: 104 str.

Zavod za gozdove Slovenije, 2019. Poročilo Zavoda za gozdove Slovenije o gozdovih za leto 2018. Zavod za gozdove Slovenije.

Zavod za gozdove Slovenije, 2019. Podatki o izbiri dreves za posek v letu 2019.

Zuur A., Leno E., Walker N., Savelie A., Smith G. 2009. Mixed effect models and extensions in ecology with R. New York, Springer Verlag: 574 str.

Citiranje: Maarten DE GROOT, Marija KOLŠEK. 2019. Kratkoročna napoved ulova osmerozobega smrekovega lubadarja (Ips typographus) v kontrolne pasti tipa Theysohn za leto 2019 za Slovenijo. Napovedi o zdravju gozdov, 2019. URL: https://www.zdravgozd.si/prognoze_zapis.aspx?idpor=51. DOI: 10.20315/NZG.51

Prispelo: 13. 08. 2019. Sprejeto: 16. 09. 2019. Objavljeno: 16. 09. 2019.

na vrh strani 